\title{
$O$ desmonte do financiamento da seguridade social em contexto de ajuste fiscal
}

\author{
The dismanting of the social insurance funding \\ in a context of fiscal adjustement
}

\begin{abstract}
Evilasio da Silva Salvador
Economista formado pela Universidade Federal de Santa Catarina, mestre e doutor em Política Social pela Universidade de Braślia — UnB, pós-doutor em Serviço Social pela Universidade do Estado do Rio de Janeiro (Uerj), professor na Universidade de Brasília (UnB). Bolsista produtividade do CNPq.
\end{abstract}

evilasioss@unb.br

Resumo: O Orçamento da Seguridade Social (OSS) é a peça-chave para a compreensão do ajuste fiscal em curso no Brasil. Este artigo analisa o desmonte do financiamento da seguridade social, a partir dos instrumentos de política fiscal como a Desvinculação de Recursos da União e as renúncias tributárias. A apropriação das contribuições sociais do OSS tem sido determinante para a política de pagamento dos juros da dívida. Ao mesmo tempo em que o OSS está inflado por despesas que são do orçamento fisscal.

Palavras-chave: Financiamento. Seguridade social. Fundo público. Orçamento. Ajuste fiscal.
Abstratct: The social insurance budget is the key to understanding the current fiscal adjustment in Brazil. This article analyzes the dismantling of social insurance funding, based on fiscal policy instruments such as the Untying Resources of Union and tax expenditure. The appropriation of the social contributions of the budget has been decisive for the policy of payment of interest of the debt. At the same time the insurance budge is inflated by expenses that are from the fiscal budget. The costs of the social security are inflated with the expenditures of the fiscal area, but whithout the due entrance of financial recourses.

Keywords: Funding. Social insurance. Public fund. Budget. Fiscal adjustment.

\section{Introdução}

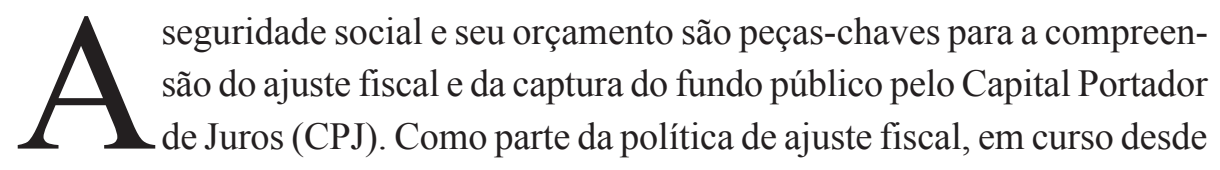
1993, que prioriza a realização de superávits primários para o pagamento de 
juros, encargos e amortização da dívida pública, o governo federal vem se apropriando das contribuições sociais destinadas à seguridade social. O corolário é o esvaziamento permanente do financiamento da seguridade social, deixando os recursos públicos liberados para os condutores das políticas econômicas atenderem os interesses do capital. Além de sustentar o discurso público de elevados "déficits previdenciários" para justificar contrarreformas previdenciárias como a apresentada pelo atual governo de plantão por meio da Proposta de Emenda Constitucional (PEC) n. 287/2016.

Outro instrumento de política fiscal que vem agravando a retirada de recursos para o financiamento da seguridade social são as renúncias tributárias sobre as contribuições sociais. Diante do agravamento da crise do capital, o governo intensificou, a partir de 2010, as concessões de renúncias fiscais para permitir a recomposição das taxas de lucros de diversos setores econômicos.

Nesse contexto, este artigo analisa o desmonte do financiamento que vem ocorrendo no Orçamento da Seguridade Social (OSS) em um contexto de ajuste fiscal e de contrarreforma do Estado. Para tanto, a próxima seção problematiza o debate sobre fundo público e a não edificação de um OSS, conforme o previsto na CF de 1988. O texto explora os dados oficiais daquilo que governo compreende como OSS por meio de uma pesquisa dos dados divulgados mensalmente pela Secretaria do Tesouro Nacional (STN) nos "Relatórios resumidos da execução orçamentária do governo federal e outros demonstrativos", evidenciando na análise os valores desviados por meio da Desvinculação de Recursos da União (DRU). O texto também apresenta uma breve investigação sobre as despesas da seguridade social por funções orçamentárias, demonstrando que o OSS está inflado com despesas que deveriam ser executadas no orçamento fiscal, conforme revelam os dados da execução orçamentária levantados no sistema Siga Brasil.

Para compreender na totalidade o desmonte do financiamento da seguridade social, o artigo explora em seção específica as renúncias tributárias, denominadas tecnicamente de gastos tributários, sendo instrumento determinante de "socorro" às empresas em momentos de crise do capitalismo. Para alcançar esses objetivos, foi realizado um levantamento dos relatórios - Demonstrativo dos Gastos Tributários - publicados no período de 2010 a 2016 pela Receita Federal e que acompanham o Projeto de Lei Orçamentária Anual (Ploa), buscando identificar 
as desonerações tributárias por tipos de tributos (contribuições sociais e impostos), o que permitiu identificar as implicações das renúncias tributárias sobre o financiamento das políticas sociais que compõem a seguridade social no Brasil.

\section{Fundo público da seguridade social e ajuste fiscal}

O fundo público ocupa um papel relevante na articulação das políticas sociais e na sua relação com a reprodução do capital, sendo uma questão estrutural do capitalismo, (Oliveira, 1998), ${ }^{1}$ envolvendo toda a capacidade de mobilização de recursos que o Estado tem para intervir na economia e nas políticas públicas (Salvador, 2012). Uma das principais maneiras da realização do fundo público é por meio da extração de recursos da sociedade na forma de impostos, contribuições e taxas, da mais-valia socialmente produzida. Portanto, conforme Behring (2012 e 2016), é parte do trabalho excedente que se transformou em lucro, juro ou renda da terra, sendo apropriado pelo Estado para o desempenho de múltiplas funções e de trabalho necessário.

O orçamento público, como a parte mais visível do fundo público (Salvador e Teixeira, 2014) não se limita a uma peça técnica e formal ou a um instrumento de planejamento. O orçamento é uma peça de cunho político que orienta as negociações a respeito de quotas de sacrifício sobre os membros da sociedade no tocante ao financiamento do Estado e é utilizado como instrumento de controle e direcionamento dos gastos, conforme Oliveira (2009), refletindo a correlação de forças sociais e políticas atuantes e que têm hegemonia na sociedade.

O fundo público exerce pelos menos quatro funções na economia capitalista: a) o financiamento do investimento capitalista, por meio de subsídios, de desonerações tributárias, por incentivos fiscais, por redução da base tributária das empresas e de seus sócios; b) a garantia de um conjunto de políticas sociais que asseguram direitos e permitem também a inserção das pessoas no mercado de consumo, independentemente da inserção no mercado de trabalho; c) assegura

1. Concorda-se com a perspectiva de Behring (2004 e 2016) que o fundo público não pode ser considerado o antivalor, como proposto por Oliveira (1998). Um debate crítico sobre a perspectiva de Oliveira (1998) pode ser visto em Salvador (2010). 
vultosos recursos do orçamento para investimentos em meios de transporte e infraestrutura, e nos gastos com investigação e pesquisa, além dos subsídios e renúncias fiscais para as empresas; d) assegura no âmbito do orçamento público a transferência na forma de juros e amortização da dívida pública para os detentores do Capital Portador de Juros (CPJ) (Salvador, 2010).

No ajuste fiscal em curso desde 1993, a DRU tem sido um importante instrumento para retirar recursos das fontes tributárias exclusivas da seguridade social. A DRU tem sua origem no antigo Fundo Social de Emergência (FSE), que já em 2004 permitia a desvinculação de $20 \%$ dos recursos destinados às políticas da seguridade social. Nos exercícios financeiros seguintes, o propósito permanece, mas o nome muda para Fundo de Estabilização Fiscal (FEF). A partir do ano 2000 passa a vigorar a DRU com sucessivas prorrogações. A mais recente ocorreu por meio da EC n. 93, de 8 de setembro de 2016, que prorroga a DRU até 31 de dezembro de 2023. O novo texto também amplia de $20 \%$ para $30 \%$ o percentual das receitas de tributos federais que podem ser usadas livremente e altera quais tributos podem ser desvinculados, incluindo os fundos constitucionais, taxas e compensações financeiras.

A DRU, como ressaltado por Boschetti e Salvador (2006), cumpre historicamente um papel de uma perversa "alquimia" de transformar os recursos destinados ao financiamento da seguridade social em recursos fiscais para a composição do superávit primário e, por consequência, os utiliza para pagar juros da dívida. Os superávits primários, no período de 2000 a 2007, foram obtidos basicamente por meio da incidência da DRU nas receitas exclusivas da seguridade social, que representaram $62,45 \%$ do superávit primário do governo federal (Salvador, 2010).

$\mathrm{O}$ atual governo brasileiro volta com carga a ortodoxia neoliberal com brutal corte de direitos sociais, sobretudo do financiamento público, como denota o Novo Regime Fiscal (NRF), aprovado pela EC n. 95. O NRF inviabiliza a vinculação dos recursos para as políticas sociais nos moldes desenhado na CF de 1988, ao congelar as chamadas despesas primárias do governo (exceto as despesas financeiras com o pagamento de juros da dívida) por vinte anos, limitando-se a correção pela inflação. Conforme Theodoro (2016), a EC n. 95 enfatiza o ajuste na redução dos gastos correntes, com consequências relevantes 
sobre as políticas sociais e a própria capacidade do Estado em regular e implementar programas e ações em prol do desenvolvimento, sendo que o pagamento de juros da dívida pública não ficará restrito a nenhum teto orçamentário.

O Brasil compromete, há pelo menos 25 anos, cerca de um terço do orçamento público anual comprometido com o pagamento de juros, encargos e amortização da dívida pública (Salvador, 2015). Em 2015, os dados do sistema Siga Brasil revelam que para o pagamento de juros e amortização da dívida foram destinados $\mathrm{R} \$ 417,25$ bilhões, isto é, $23,71 \%$ do orçamento executado naquele ano. As despesas com os juros nominais, que implicam a necessidade da rolagem da dívida pública, alcançaram o valor histórico de $\mathrm{R} \$ 501,8$ bilhões, isto é, 9\% do PIB (Lacerda, 2016).

O fundo público da seguridade social deveria ser construído, a partir das determinações constitucionais, com a criação de um orçamento da seguridade social (art. 165, $\S 5^{\circ}$, inciso III), visando enfrentar a perversa tradição fiscal brasileira de insuficiência de recursos para as políticas sociais. O OSS deveria ser elaborado "de forma integrada pelos órgãos responsáveis pela saúde, previdência social e assistência social, tendo em vista as metas e prioridades estabelecidas na Lei de Diretrizes Orçamentárias e assegurada a cada área a gestão de seus recursos", conforme estabelecido na CF, art. $195, \S 2^{\circ}$. O corolário das determinações constitucionais seria a constituição de um fundo público exclusivo da seguridade social com a canalização de recursos próprios e exclusivos para as políticas de saúde, da previdência e da assistência social, além do seguro-desemprego, distinto daquele que financia as demais políticas de governo. O orçamento da seguridade social no formato previsto na CF virou "letra morta" (Salvador, 2010). O ajuste fiscal tem implicado de forma permanente o (des) financiamento da seguridade social e corroborado com um discurso público de elevados "déficit previdenciários" como justificativas para contrarreformas ${ }^{2}$ previdenciárias.

Do ponto de vista constitucional, não existe sequer a previsão de um orçamento da previdência social. A Constituição brasileira definiu no seu artigo

2. Adota-se aqui a perspectiva apontada por Behring (2003) da contrarreforma e da recuperação histórica do termo "reforma" feito por Coutinho (2010), assinalando que o termo foi sempre organicamente ligado às lutas dos subalternos para transformar a sociedade com uma conotação claramente progressista, sendo deturpado e mitificado pelo neoliberalismo. 
165, para os três níveis de governo, que a LOA será composta pelo Orçamento Fiscal, Orçamento de Investimentos das Empresas Estatais e Orçamento da Seguridade Social. O que tradicionalmente o governo brasileiro divulga é o resultado financeiro do Regime Geral da Previdência Social (RGPS) por meio do contraste entre a arrecadação líquida e as despesas com benefícios previdenciários dos trabalhadores do setor privado (Salvador, 2010).

Em 2004 ocorreu pela primeira vez a separação do orçamento fiscal e da seguridade social, mas tal fato aconteceu apenas de maneira formal, sem ser uma iniciativa articulada e sistêmica dos órgãos responsáveis pela seguridade social. Assim, a peça chamada de OSS que integra a LOA não corresponde às expectativas do desenho orçamentário previsto na CF de 1988. Em que pese a existência legal do OSS, "a seguridade social no Brasil nunca se constitui na prática, sendo seu processo de implantação interrompido" (Soares, 2003, p. 8). Com isso, as políticas vinculadas ao sistema de seguridade social, tanto do ponto vista do seu financiamento quanto dos gastos, foram constrangidas, não universalizando direitos.

A não implementação do orçamento da seguridade social, conforme o dito constitucional, também ajudou a criar o caldo de cultura da crise da seguridade social (Mota, 2000), pois constituiu um elemento importante para as justificativas de contrarreformas previdenciárias. $\mathrm{O}$ argumento do déficit previdenciário tem sido recorrente ao longo dos últimos 28 anos e serviu de justificativa para as contrarreformas previdenciárias de 1998 (EC n. 20) e de 2003 (EC n. 41) e para apresentação no tempo presente de uma nova contrarreforma da previdência social. ${ }^{3}$

Diversos estudos (Delgado, 2002; Boschetti, 2003; Gentil, 2006; Salvador, 2010; Anfip, 2016) têm desmitificado o chamado "déficit da previdência social", a partir do apontamento do OSS da CF de 1988. O artigo 195 da Constituição determina uma diversidade de fontes de financiamento exclusivas para o custeio dos direitos relativos a saúde, previdência social e assistência social e também

3. Não é o objetivo deste artigo analisar a atual proposta de "reforma" da previdência social formulada no âmbito da PEC n. 287/2016. Uma boa coletânea de artigos críticos sobre a atual "reforma" pode ser visto na revista SER Social, n. 39, publicada em dezembro/2016. Vide também o extenso documento produzido pela Anfip e Dieese (2017). 
do seguro-desemprego. Essas fontes são as contribuições sociais: Contribuição Social para o Financiamento da Seguridade Social (Cofins), Contribuição Social sobre o Lucro Líquido (CSLL), Contribuição Social do PIS/Pasep e a contribuição de empregados e empregadores para a seguridade social. Além dos recursos dos concursos de prognósticos.

Nesse cenário, torna-se relevante conhecer os dados oficiais da seguridade social naquilo que o governo federal entende como OSS, que é divulgado mensalmente, na forma da execução das receitas e despesas nos "Relatórios resumidos da execução orçamentária do governo federal e outros demonstrativos" da Secretaria do Tesouro Nacional (STN). Nesses relatórios também é possivel descobrir os valores "surrupiados" pela DRU da seguridade social, conforme Tabela 1. Convém destacar que esses resultados são diferentes daqueles divulgados anualmente pela Associação Nacional do Auditores Fiscais da Receita Federal do Brasil (Anfip), ${ }^{4}$ pois a entidade busca divulgar o OSS mais próximo do previsto na CF de 1988.

O governo federal inclui no OSS tanto na Lei Orçamentária Anual (LOA), como nos resultados divulgados pela $\mathrm{STN}$, todas as despesas previdenciárias tanto do RGPS, como as do Regime Próprio de Previdência (RPP) do setor público, além de despesas com benefícios dos servidores públicos federais e os gastos com saúde dos militares. Esses gastos (acertadamente) não são considerados nos resultados apurados pela Anfip. A instituição também inclui no montante das receitas os valores desviados pela DRU, o que resultaria em um OSS superavitário bem diferente das contas oficiais. Assim, o chamado OSS, na contabilidade oficial, está inflado por despesas que deveriam ser do orçamento fiscal e está subestimado nas receitas, pois não considera os valores desviados pela DRU e pelas renúncias tributárias.

Como pode ser verificado na Tabela 1, desde 2008 a DRU não tem, nos dados oficiais, o mesmo impacto sobre as contas da seguridade social como teve no período de 2000 a 2007 (Salvador, 2010). Com a extinção da Contribuição Provisória sobre Movimentação Financeira (CPMF), o OSS deixou de registrar superávits nas contas oficiais da STN a partir de 2009, conforme a Tabela 1.

4. A Anfip divulga anualmente uma análise do orçamento da seguridade social. Disponível em: $<$ http:// www.anfip.org.br/publicacoes/home>. Acesso em: 15 maio 2017. 
Tabela 1 - Receitas, despesas da seguridade social

Valores em R\$ bilhões, deflacionados pelo IGP-DI, a preços médios de 2016

\begin{tabular}{|c|c|c|c|c|c|c|}
\hline Ano & Receitas & Despesas & Saldo & DRU (1) & $\begin{array}{c}\text { Renúncias } \\
\text { Tributárias (2) }\end{array}$ & $\begin{array}{c}\text { Total (des)Financiamento } \\
\text { do 0SS (1) + (2) }\end{array}$ \\
\hline 2008 & 597,29 & 656,77 & $-59,48$ & 71,65 & 33,86 & 105,51 \\
\hline 2009 & 663,71 & 776,39 & $-112,68$ & 63,75 & 48,43 & 112,17 \\
\hline 2010 & 652,03 & 762,73 & $-110,70$ & 69,87 & 98,09 & 167,96 \\
\hline 2011 & 711,98 & 808,47 & $-96,48$ & 76,41 & 104,26 & 180,66 \\
\hline 2012 & 729,88 & 838,50 & $-108,63$ & 76,47 & 125,44 & 201,92 \\
\hline 2013 & 770,91 & 881,06 & $-110,15$ & 79,16 & 152,73 & 231,89 \\
\hline 2014 & 750,76 & 919,29 & $-168,53$ & 74,31 & 169,46 & 243,78 \\
\hline 2015 & 710,30 & 938,33 & $-228,03$ & 86,03 & 185,70 & 271,72 \\
\hline 2016 & 680,65 & 949,53 & $-268,89$ & 101,09 & 168,41 & 269,50 \\
\hline
\end{tabular}

Fonte: Secretaria do Tesouro Nacional (STN) - relatórios resumidos da execução orçamentária do governo federal e outros demonstrativos e da Receita Federal do Brasil (RFB) — relatórios dos demonstrativos de gastos tributários.

Elaboração própria.

Mesmo após 2008, os efeitos da DRU sobre as políticas da seguridade social continuam perversos, pois ao deixar para "livre" gestão do comando econômico feito pelos Ministérios da Fazenda e de Planejamento, os recursos que deveriam ser destinados exclusivamente para as políticas da seguridade social acabam sendo um importante instrumento de gestão fiscal para contingenciamento de recursos orçamentários, com a finalidade de assegurar temporariamente superávit primário durante o ano, limitando os gastos das áreas sociais aos previstos constitucionalmente (Salvador, 2012). Os recursos que retornam do orçamento para o OSS acabam sendo alocados em benefícios, em detrimento dos investimentos e gastos com serviços de saúde e socioassistenciais.

Na Tabela 1 é possível também visualizar as implicações nas receitas da seguridade social que advêm das medidas tomadas pelo governo brasileiro por meio das renúncias tributárias para socorrer o capital, que constituem um verdadeiro desmonte do financiamento da seguridade social. Destacam-se, sobretudo, as políticas de desonerações tributárias das contribuições sociais e a desoneração da folha de pagamento, que afetam o financiamento do orçamento da seguridade social (Salvador, 2015). 
Levando em conta as renúncias tributárias, a partir de 2010, quando estão incluídas as renúncias previdenciárias referente às contribuições de empregadores e empregados para seguridade social (folha pagamento), verifica-se, na Tabela 1, o expressivo crescimento de 71,69\% acima da inflação, evoluindo de R \$ 98,09 bilhões (2010) para R \$ 168,41 bilhões (2016). O (des)financiamento do OSS com a retirada de recursos por meio da DRU e das renúncias tributárias alcançou o montante de R $\$ 269,50$ bilhões em 2016 (Tabela 1), isto é, 37,60\% acima dos recursos que foram destinados no mesmo ano para as políticas de saúde e assistência social no orçamento da União, que totalizaram o montante R\$ 195,86 bilhões (vide Tabela 2).

Esses valores indicam que o OSS, mesmo pelas contas oficiais, que estão longe do orçamento determinado pela CF de 1988, seria superavitário, caso fossem devolvidos os recursos retirados por meio da DRU e das renúncias tributárias à seguridade social.

Tabela 2 - Orçamento da Seguridade Social, por funções

Valores em R\$ bilhões, deflacionados pelo IGP-DI, a preços médios de 2016

\begin{tabular}{|l|c|c|c|c|c|c|}
\hline Ano & $\begin{array}{c}\text { Assistência } \\
\text { Social }\end{array}$ & $\begin{array}{c}\text { Previdência } \\
\text { Social }\end{array}$ & Saúde & Trabalho & $\begin{array}{c}\text { Outras } \\
\text { Funções }\end{array}$ & Total 0SS \\
\hline 2008 & 51,50 & 435,73 & 80,47 & 37,70 & 20,27 & 625,67 \\
\hline 2009 & 53,64 & 450,54 & 80,65 & 44,29 & 25,12 & 654,24 \\
\hline 2010 & 61,86 & 500,07 & 88,68 & 47,22 & 28,63 & 726,45 \\
\hline 2011 & 67,91 & 523,97 & 96,64 & 52,29 & 28,80 & 769,61 \\
\hline 2012 & 75,17 & 536,74 & 99,60 & 55,59 & 28,91 & 796,00 \\
\hline 2013 & 79,97 & 565,85 & 100,80 & 59,40 & 29,58 & 835,61 \\
\hline 2014 & 82,96 & 585,35 & 107,14 & 63,32 & 31,84 & 870,61 \\
\hline 2015 & 78,74 & 606,05 & 110,57 & 55,10 & 36,92 & 887,38 \\
\hline 2016 & 85,46 & 638,97 & 110,40 & 60,16 & 36,87 & 931,86 \\
\hline Var. \% & $65,95 \%$ & $46,64 \%$ & $37,20 \%$ & $59,56 \%$ & $81,88 \%$ & $48,94 \%$ \\
\hline
\end{tabular}

Fonte - Siga Brasil.

Elaboração própria. 
Os resultados divulgados pela STN não permitem um detalhamento por funções orçamentárias. Para tanto, foram extraídas informações da execução anual do OSS, na base de dados pública do Sistema Siga Brasil, para a organização da Tabela 2. O Siga Brasil é um sistema desenvolvido pelo Senado Federal que reúne um grande acervo de dados orçamentários em um único site na internet, disponibilizando também senha de especialista para o estudo dos dados. As fontes de dados disponibilizadas no Siga Brasil referem-se à execução orçamentária do governo federal feita pelo Sistema Integrado de Administração Financeira do Governo Federal (Siafi) e pelo Sistema Integrado de Dados Orçamentários (Sidor), que constituem a base das informações mensais coletadas que se relacionam com os registros do Orçamento e do Balanço Geral da União.

Chama a atenção na Tabela 2, em comparação com a Tabela 1, que as despesas de seguridade social extraídas anualmente da execução das leis orçamentárias anuais não coincidem com valores divulgados pela STN, em dezembro de cada ano. É interessante notar que são duas bases públicas de dados e que "em tese" não deveriam apresentar tamanha discrepância dentro do mesmo orçamento. Em 2009, por exemplo, há uma diferença de R \$ 122,15 bilhões, a maior nas despesas da seguridade social nos valores divulgados pela STN. Tal situação enseja maior investigação dessas informações, mas também revela a necessidade de muita cautela com as informações divulgadas oficialmente pelo governo, que tende, geralmente, a inflar as despesas da seguridade social, notadamente da previdência social, a fim de justificar as propostas de cortes dos direitos sociais.

Os dados da Tabela 2 revelam que o OSS, no período de 2008 a 2016, não executou apenas as funções típicas vinculadas à seguridade social (assistência social, previdência, saúde e trabalho), mas em todos os anos foram pagos com recursos exclusivos da seguridade social outras despesas estranhas a esse orçamento. Aliás, foram exatamente as despesas pagas em "outras funções" no orçamento aquelas que apresentaram o maior crescimento no período em tela, evoluindo $81,88 \%$ acima da inflação (medida pelo IGP-DI), bem superior à evolução de 48,94\% do OSS. Uma clara demonstração de apropriação indevida do OSS com despesas típicas do orçamento fiscal, sem o devido aporte de recursos ordinários, provenientes de impostos.

No período de 2008 a 2016 observa-se o crescimento real de 65,95\% na função assistência social, que aumentou sua participação no OSS, alcançando o 
montante de $\mathrm{R} \$ 85,46$ bilhões em 2016 (Tabela 2). Contudo, como destacado por Boschetti, Teixeira e Salvador (2013), os recursos destinados à política de assistência social, desde 2003, concentram-se basicamente no pagamento de dois benefícios: o Benefício de Prestação Continuada (BPC) da assistência social e a transferência de renda com condicionalidades no âmbito do Programa Bolsa Família (PBF).

A Tabela 2 revela o subfinanciamento crônico da saúde, muito aquém dos recursos públicos necessários para a universalização dessa política; A política de saúde nunca conseguiu alcançar 30\% do OSS. No período de 2008 a 2016, a função saúde perdeu espaço no conjunto das despesas que integram o OSS, decrescendo de $12,86 \%$ em 2008 , do montante das despesas da seguridade social, para $11,85 \%$ do OSS em 2016.

As despesas executadas na função previdência social não corroboram para o discurso corrente do governo de descontrole das contas previdenciárias. A Tabela 2 revela que a função previdência social não acompanhou sequer o crescimento do montante dos recursos destinados no âmbito do OSS. É importante ressaltar que nos dados da função previdência social da Tabela 2, o governo também paga os benefícios previdenciários dos servidores públicos federais (civis e militares), que, por princípios constitucionais, não incluiriam esse tipo de gasto. Um detalhamento da execução orçamentária de 2016 da função previdência social, por ações, a partir dos dados sistema Siga Brasil, revela que foram destinados ao pagamento de aposentadorias e pensões de servidores civis o total de $\mathrm{R} \$ 65,65$ bilhões e mais $\mathrm{R} \$ 17,34$ bilhões ao custeio das pensões militares das Forças Armadas.

Conforme Delgado (2002), em que pese serem legítimas as despesas com inativos e pensionistas da União, esses dispêndios devem pertencer ao fiscal, o qual é financiado por tributos, e não por recursos próprios do OSS. A Constituição de 1988 não inclui a previdência do servidor público no capítulo específico que trata da seguridade social (Salvador, 2010).

\section{Renúncias tributárias e a retirada de recursos da seguridade social}

Com o acirramento da crise do capitalismo e seus efeitos retardatários no Brasil, o governo federal vem adotando como uma das estratégias para o socorro 
ao capital e a retomada das taxas de lucros do setor não financeiro da economia, a concessão de generosos incentivos fiscais - tecnicamente conhecidos como gastos tributários - a empresas, sem o controle democrático da sociedade e sem contrapartidas sociais. As renúncias tributárias comprometem o financiamento da seguridade social, assim como os fundos de participação dos estados e dos municípios, que são formados a partir da arrecadação dos impostos federais. Com isso, além do esvaziamento do financiamento da seguridade social na esfera federal, também ocorre uma diminuição de recursos dos fundos de participação de estados e municípios, implicando um menor volume de transferências para os gastos orçamentários dos entes subnacionais com educação e saúde (Salvador, 2015).

As renúncias tributárias são denominadas legalmente de gastos tributários, que são desonerações equivalentes a gastos indiretos de natureza tributária. São consideradas exceções à regra do marco legal tributário, mas presentes no código tributário com o objetivo de aliviar a carga tributária de uma classe específica de contribuintes, de um setor econômico ou de uma região (Beghin, Chaves e Ribeiro, 2010).

Villela, Lemgruber e Jorratt (2009) destacam certo consenso, na literatura internacional, em relação ao conceito de gastos tributários no sentido de que são as receitas que o Estado deixou de arrecadar em virtude da aplicação de concessões ou de regimes fiscais, sendo uma das ferramentas de que os governos dispõem para executar as políticas públicas. Sua finalidade é favorecer ou promover determinados setores, atividades, regiões ou agentes econômicos. Conforme os autores, os gastos tributários também são chamados de "renúncia fiscal", em alusão ao fato de que, dessa forma, o Estado desiste de parte ou de toda a aplicação do regime fiscal geral, com base em um objetivo maior da política econômica ou social. Contudo, tal consenso não ocorre sobre os caminhos metodológicos adotados para a apuração desses gastos.

Para a Receita Federal do Brasil (RFB, 2013), os gastos tributários são despesas indiretas que, em princípio, poderiam ser substituídas por um gasto público alocado no orçamento e aparecem no sistema tributário por meio de isenções, deduções, abatimentos, imunidades, presunções creditícias e outros benefícios de natureza tributária, reduzindo a arrecadação potencial do tributo.

Em consonância com a Constituição de 1988, o Projeto de Lei Orçamentária (Ploa) deve vir acompanhado do relatório das estimativas dos gastos tributários, 
sendo elaborado pela Secretaria da Receita Federal do Brasil (RFB), mas, em geral, sem o controle democrático desses gastos (Teixeira, 2012). O conceito de gastos tributários para a RFB (2013) refere-se aos dispêndios indiretos do governo realizados por intermédio do sistema tributário, visando alcançar objetivos econômicos e sociais. Conforme o órgão responsável pela arrecadação federal dos tributos (RFB, 2013), os gastos tributários reduzem a entrada de receitas para o Estado e aumentam a disponibilidade econômica do contribuinte.

Os gastos tributários federais, no período de 2010 a 2016, estão consolidados na Tabela 3, a partir dos dados da RFB, e foram deflacionados pelo IGP-DI, a preços médios de 2016. Os dados da Tabela 3 foram extraídos dos relatórios da RFB (2013, 2014, 2015). Anualmente o órgão publica o relatório "Demonstrativos dos gastos tributários", que acompanha o Ploa. Em 2013, a RFB publicou um documento intitulado "Demonstrativo dos gastos tributários: estimativas das bases efetivas" para atender tanto a demanda dos órgãos de controle quanto as organizações representativas da sociedade por informações sobre a realização dos gastos tributários efetivos.

A diferença metodológica entre os documentos diz respeito ao fato de que o "Demonstrativo dos gastos tributários" que acompanha o Ploa (RFB, 2014 e 2015) apresenta as projeções dos gastos tributários com informações disponíveis até o mês de agosto ${ }^{5}$ do ano anterior do orçamento que será votado pelo Congresso Nacional. Já no relatório divulgado a partir das bases efetivas (RFB, 2013), os gastos tributários são atualizados, acompanhando as mudanças das variáveis econômicas em que foram baseadas as estimativas e projeções do relatório que acompanhou o Ploa, além de refletir a disponibilidade de novas fontes de informações e aprimoramentos na metodologia empregada nas estimativas e projeções (Salvador, 2015).

A Tabela 3 revela um crescimento expressivo das renúncias tributárias (gastos tributários) no período de 2010 a 2016, evoluindo de $\mathrm{R} \$ 217,27$ bilhões (2010) para R \$ 319,23 bilhões (2016), isto é, um crescimento 46,93\% acima da inflação. No mesmo período, o orçamento fiscal e da seguridade social aumentou, em termos reais, apenas $28,28 \%$ (Tabela 2). Portanto, as renúncias tributárias

5. O projeto de lei que trata do orçamento anual deve ser enviado pelo Poder Executivo ao Congresso Nacional até o dia 31 de agosto. 
implicaram uma perda de arrecadação equivalente a 20,68\% das receitas do governo federal ou 4,33\% do PIB. Esses recursos que o fundo público deixa de contar significam, em grande parte, um financiamento para o capital.

Tabela 3 - Gastos tributários de 2010 a 2016, por tipos de tributos

Valores em R\$ bilhões, deflacionados pelo IGP-DI, a preços médios de 2016

\begin{tabular}{|c|c|c|c|c|c|c|c|c|}
\hline \multirow{2}{*}{ Tributos } & \multicolumn{3}{|c|}{ Estimativas de bases efetivas } & \multicolumn{4}{|c|}{ Projeção } & \multirow{2}{*}{$\begin{array}{r}\text { Variação } \\
\text { de } 2010 \text { a } \\
2016 \text { em \% }\end{array}$} \\
\hline & 2010 & 2011 & 2012 & 2013 & 2014 & 2015 & 2016 & \\
\hline $\begin{array}{l}\text { Gastos tributários - } \\
\text { Impostos (1) }\end{array}$ & 119,18 & 125,14 & 126,23 & 132,94 & 138,81 & 144,95 & 149,47 & $25,42 \%$ \\
\hline $\begin{array}{l}\text { Contribuição Social } \\
\text { para o PIS-Pasep }\end{array}$ & 9,70 & 10,32 & 11,64 & 14,00 & 14,44 & 16,61 & 15,18 & $56,51 \%$ \\
\hline $\begin{array}{l}\text { Contribuição Social } \\
\text { sobre o Lucro } \\
\text { Líquido - CSLL }\end{array}$ & 9,81 & 10,13 & 11,42 & 11,71 & 11,54 & 12,36 & 13,16 & $34,14 \%$ \\
\hline $\begin{array}{l}\text { Contribuição para } \\
\text { o Financiamento da } \\
\text { Seguridade Social } \\
\text { — Cofins }\end{array}$ & 49,91 & 52,86 & 59,47 & 70,78 & 72,62 & 83,09 & 76,05 & $52,38 \%$ \\
\hline $\begin{array}{l}\text { Contribuição para a } \\
\text { Previdência Social }\end{array}$ & 28,68 & 30,95 & 42,91 & 56,24 & 70,86 & 73,64 & 64,02 & $123,25 \%$ \\
\hline $\begin{array}{l}\text { Gastos tributários } \\
\text { — Contribuições } \\
\text { Sociais (2) }\end{array}$ & 98,09 & 104,26 & 125,44 & 152,73 & 169,46 & 185,70 & 168,41 & $71,68 \%$ \\
\hline $\begin{array}{l}\text { Outros gastos } \\
\text { tributários (3) }\end{array}$ & - & 1,45 & 1,60 & 1,64 & 1,70 & 2,04 & 1,35 & - \\
\hline $\begin{array}{l}\text { Total dos gastos } \\
\text { tributários }\end{array}$ & 217,27 & 230,84 & 253,28 & 287,32 & 309,98 & 332,70 & 319,23 & $46,93 \%$ \\
\hline $\begin{array}{l}\text { Gastos tributários/ } \\
\text { arrecadação em \% }\end{array}$ & $17,52 \%$ & $16,24 \%$ & $18,30 \%$ & $19,84 \%$ & $20,66 \%$ & $21,11 \%$ & $20,68 \%$ & - \\
\hline $\begin{array}{l}\text { Gastos tributários/ } \\
\text { PIB em \% }\end{array}$ & $3,60 \%$ & $3,68 \%$ & $4,12 \%$ & $4,51 \%$ & $4,76 \%$ & $4,93 \%$ & $4,33 \%$ & - \\
\hline
\end{tabular}

Fonte: RFB (2013, 2014, 2015).

Elaboração própria.

Notas:

1. Refere-se à soma dos seguintes impostos: Imposto sobre importação (II), Imposto sobre a Renda Pessoa Física (IRFP), Imposto sobre a Renda de Pessoa Jurídica (IRPJ), Imposto sobre Produtos Industrializados (IPI), Imposto sobre Operações Financeiras (IOF) e Imposto sobre Propriedade Territorial Rural (ITR).

2. Refere-se à soma das seguintes contribuições sociais: PIS-Pasep, Cofins, CSLL e contribuição para a previdência social.

3. Refere-se à soma do adicional de frete para renovação da marinha mercante e a Contribuição de Intervenção no Domínio Econômico (Cide). 
A Tabela 3 apresenta os dados por tributos (impostos e contribuições sociais) e revela que, enquanto as desonerações de impostos cresceram 25,42\%, os gastos tributários advindos das contribuições sociais (Cofins, PIS, CSLL e contribuições previdenciárias) que financiam a seguridade social tiveram uma evolução de $71,68 \%$ em termos reais. Portanto, as renúncias tributárias concedidas pelo governo federal em favor do capital, nos últimos anos, retiraram recursos das fontes orçamentárias que financiam as políticas de previdência social, assistência social, saúde e seguro-desemprego.

O Gráfico 1 mostra que, no período de 2010 a 2016, ocorreu uma inversão nas renúncias tributárias. Até 2012, a maior parte das renúncias tributárias ocorria sobre os impostos. A partir de 2013, a situação se inverte, e os gastos tributários advindos das contribuições sociais passam a responder por mais da metade da perda de arrecadação de tributos da União, sendo que em 2015 esse percentual respondeu por 55,82\%, conforme o Gráfico 1 .

Gráfico 1 - Participação das contribuições sociais e dos impostos sobre o total dos gastos tributários, no período de 2010 a 2016

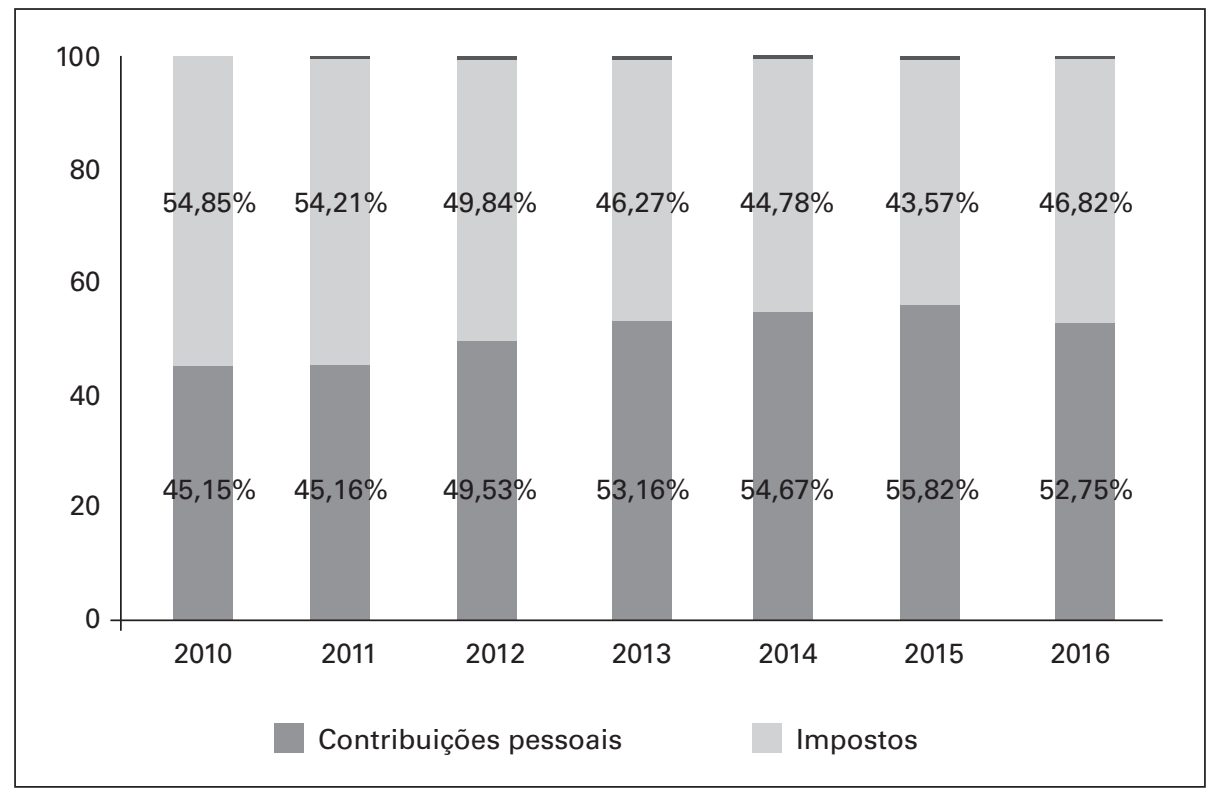

Fonte: RFB (2013, 2014, 2015).

Elaboração própria. 
O que justifica o expressivo aumento dos gastos tributários nas contribuições sociais são, sobretudo, as desonerações das contribuições previdenciárias sobre a folha de pagamento e da Cofins, que o governo vem concedendo a diversos setores da economia. De acordo com a Tabela 3, essas duas contribuições sociais deixaram de arrecadar, por conta das renúncias tributárias, R \$ 140,07 bilhões em 2016, o que significou 83,17\% dos gastos tributários das contribuições sociais.

O relatório "Demonstrativo dos gastos tributários - Ploa 2016" da RFB (2015) fornece pistas das renúncias tributárias sobre as contribuições previdenciárias. Conforme a RFB (2015), os gastos tributários da "contribuição para a previdência social" devem responder por $20,05 \%$ das renúncias tributárias em 2016. As três principais desonerações, em 2016, que atingem a contribuição para previdência social, em valores correntes, são: a desoneração sobre folha de pagamento ( $\mathrm{R} \$ 14,5$ bilhões), a não cobrança da contribuição previdenciária patronal das entidades filantrópicas (R $\$ 11,01$ bilhões) e o chamado Simples Nacional (R \$ 20,63 bilhões), que é um regime especial unificado de arrecadação de tributos e contribuições devidos pelas microempresas e empresas de pequeno porte. Também merece destaque a imunidade tributária concedida ao agronegócio exportador, o que implica a necessidade de maior cobertura financeira do subsistema previdenciário rural. No ano de 2016, essa renúncia estava estimada em R \$ 6,5 bilhões (RFB, 2016). Conforme a Anfip (2013), essa situação implica a necessidade de maior solidariedade entre os trabalhadores urbanos e rurais. Essas desonerações da folha de pagamento afetam diretamente o Orçamento da Seguridade Social (OSS), pois a Contribuição de Empregados e Empregadores, que integra a contribuição sobre a folha de pagamento, representa mais da metade do OSS, de acordo com Salvador (2010).

Conforme Salvador (2015), a partir de 2010 foram tomadas diversas medidas de socorro ao capital no país, envolvendo a prorrogação da redução do IPI para a indústria automobilística e a redução do IPI dos eletrodomésticos da chamada linha branca (geladeiras, fogões, máquinas de lavar). Em agosto de 2011, foi lançado o plano Brasil Maior, sob o argumento de aumentar a competitividade da indústria nacional, a partir do incentivo à inovação tecnológica e à agregação de valor, sendo que chave-mestra do plano foi constituída pelas desonerações tributárias - como a redução de IPI sobre bens de investimento, 
redução gradual do prazo para devolução dos créditos do PIS-Pasep/Cofins sobre bens de capital e a desoneração da contribuição previdenciária incidente sobre a folha de pagamento para alguns segmentos econômicos (confecção, calçados, móveis e softwares) —, que serão compensadas no faturamento das empresas desses segmentos. Diante do agravamento da crise do capital, essas medidas foram ampliadas em 2012.

Em abril de 2012, ampliaram-se as desonerações tributárias por meio da substituição da contribuição previdenciária patronal sobre a folha de pagamento (20\% do INSS) de quinze setores da indústria por uma alíquota entre 1,5\% e 2,5\% sobre o faturamento bruto das empresas. A desoneração da folha de pagamento foi sendo ampliada, alcançando, em janeiro de 2014, 56 segmentos da economia (dos setores de indústria, serviços, transportes, construção e comércio), conforme Zanghelini et al. (2013). Essa desoneração implica um volume significativo de recursos renunciados do OSS.

\section{Considerações finais}

A apropriação de recursos vinculados ao Orçamento da Seguridade Social (OSS) vai ser fundamental para a viabilização do ajuste fiscal, implodindo a vinculação de recursos previstos originalmente na Constituição Federal (CF) de 1988. Com isso a seguridade social vivencia um desmonte no seu financiamento. No âmbito do ajuste fiscal construído, a partir de 1993 foram engendrados mecanismos de desvinculação de recursos que atingiram, sobretudo, o financiamento da seguridade.

Desde 2000, vigora no país a DRU, que foi novamente prorrogada até 2023 e ampliada para 30\%, agravando ainda mais a drenagem de recursos da seguridade social para viabilizar o pagamento de juros, encargos e amortização da DRU. No bojo das medidas de ajuste fiscal aprovadas nesse ano, destaca-se o NRF (EC n. 95), que estabelece um teto para os gastos sociais, sepultando as vinculações orçamentárias das políticas sociais construídas na CF de 1988. Com isso, tanto as políticas que integram a seguridade social (previdência social, assistência social e saúde), como também o seguro-desemprego e a educação terão seus recursos orçamentários diminuídos, em termos reais, nos 
próximos vinte anos, inviabilizando a garantia e até mesmo a expansão dos direitos sociais.

Este artigo também joga luz sobre outro mecanismo de desmonte do financiamento da seguridade social, que são as renúncias tributárias, conhecidas como gastos tributários. A situação do orçamento da seguridade agrava-se com as renúncias tributárias concedidas sobre as contribuições sociais, que deveriam ser exclusivas para o financiamento da previdência social, assistência social, saúde e seguro-desemprego. Conforme demonstrado ao longo do texto, o OSS seria superavitário, mesmo nas contas oficiais, caso fossem devolvidos os recursos surrupiados das contribuições sociais da seguridade social.

No lado das despesas o OSS encontra-se inflado por despesas que deveriam ser do orçamento fiscal, notadamente as que se referem à cobertura dos direitos previdenciários dos servidores públicos. No orçamento da seguridade social também vem ocorrendo a execução de conjunto de despesas em funções que não dizem respeito às políticas de saúde, previdência social e assistência social. Ressalva-se ainda a discrepância das bases públicas de dados orçamentários que apontam para o mesmo orçamento diferenças relevantes de valores.

Diante do desmonte do financiamento da seguridade social, não há sustentação econômica para realização de uma nova "reforma" da previdência social sem a devida devolução dos recursos que são desviados anualmente do OSS para o pagamento de juros da dívida pública e para o socorro ao capital.

Recebido em 27/4/2017 a Aprovado em 12/6/2017

\section{Referências bibliográficas}

ANFIP. Análise da seguridade social 2012. Brasília: Anfip, 2013. . Análise da seguridade social 2016. Brasília: Anfip, 2016.

; DIEESE. Previdência: reformar para excluir? Brasília: Anfip, Dieese, 2017. 
BEGHIN, Nathalie; CHAVES, José; RIBEIRO, José. Gastos tributários sociais de âmbito federal: uma proposta de dimensionamento. In: CASTRO, Jorge; SANTOS, Cláudio; RIBEIRO, José (Orgs.). Tributação e equidade no Brasil. Brasília: Ipea, 2010. p. 375-408.

BEHRING, Elaine. Brasil em contrarreforma: desestruturação e perdas de direitos. São Paulo: Cortez, 2003.

. Política social: notas sobre o presente e o futuro. In: BOSCHETTI, Ivanete et al. (Orgs.). Política social: alternativas ao neoliberalismo. Brasília: UnB, 2004. p. 161-180. . Rotação do capital e crise: fundamentos para compreender o fundo público e a política social. In: SALVADOR, Evilasio et al. (Orgs.). Financeirização, fundo público e política social. São Paulo: Cortez, 2012. p. 153-180.

. Fundo público: um debate estratégico e necessário. In: XV ENCONTRO NACIONAL DE PESQUISADORES EM SERVIÇO SOCIAL (ENPESS), 2016, Ribeirão Preto. "20 anos de diretrizes curriculares, 70 de Abepss e 80 de Serviço Social no Brasil. Formação e trabalho profissional - reafirmando as diretrizes curriculares da Abepss". Anais. Brasília: Abepss, 2016.

BOSCHETTI, Ivanete Salete. Implicações da reforma da previdência na seguridade social brasileira. Psicologia \& Sociedade, Porto Alegre, v. 15, n. 1-2003, p. 57-96, 2003.

; SALVADOR, Evilasio. Orçamento da seguridade social e política econômica: perversa alquimia. Serviço Social \& Sociedade, São Paulo, v. 87, p. 25-57, 2006.

; TEIXEIRA, Sandra; SALVADOR, Evilasio. Assistência social após 20 anos de LOAS: fim da travessia do deserto? In: SILVA, Marluce (Org.). Gerontologia: saúde, assistência e previdência. Cuiabá: Ed. UFMT, 2014.

COUTINHO, Carlos. A hegemonia da pequena política. In: OLIVEIRA, F.; BRAGA, R.; RIZEC, C. (Orgs.). Hegemonia às avessas: economia, política, na era da servidão financeira. São Paulo: Boitempo, 2010. p. 29-43.

DELGADO, Guilherme. O orçamento da seguridade social precisa ser recuperado. Políticas Sociais, Brasília, n. 5, p. 111-114, ago. 2002.

GENTIL, Denise. Politica fiscal e falsa crise da seguridade social brasileira: análise financeira do período 1990-2005. Dissertação (Doutorado em Economia) Universidade Federal do Rio de Janeiro, Rio de Janeiro, 2006. 
LACERDA, Antonio. Riscos e potencialidades da economia brasileira. Economistas, Brasília, n. 19, mar. 2016, p. 19-26.

MOTA, Ana. Cultura da crise seguridade social. São Paulo: Cortez, 2000.

OLIVEIRA, Fabrício. Economia e política das finanças públicas no Brasil. São Paulo: Hucitec, 2009.

OLIVEIRA, Francisco. Os direitos do antivalor: a economia política da hegemonia imperfeita. Petrópolis: Vozes, 1998.

RFB. Demonstrativo dos gastos tributários - PLOA 2014. Brasília: Secretaria da Receita Federal do Brasil, 2013.

. Demonstrativo dos gastos tributários - PLOA 2015. Brasília: Secretaria da Receita Federal do Brasil, 2014.

. Demonstrativo dos gastos tributários - PLOA 2016. Brasília: Secretaria da Receita Federal do Brasil, 2015.

. Demonstrativo dos gastos tributários: estimativas de bases efetivas - 2011. Série 2009 a 2013. Brasília: Secretaria da Receita Federal do Brasil, 2013.

RFB. Demonstrativo dos Gastos Tributários - PLOA 2017. Brasília: Secretaria da Receita Federal do Brasil, 2016.

SALVADOR, Evilasio. Fundo público e seguridade social no Brasil. São Paulo: Cortez, 2010.

. Fundo público e financiamento das políticas sociais no Brasil. Serviço Social em Revista (on-line), v. 14, p. 4-22, 2012.

. Os impactos das renúncias tributárias no financiamento das políticas sociais no Brasil. Brasília: Inesc, 2015.

; TEIXEIRA, Sandra. Orçamento e políticas sociais: metodologia de análise na perspectiva crítica. Revista de Políticas Públicas, São Luís, v. 18, p. 15-32, 2014.

SER SOCIAL. Previdência social e trabalho. Brasília: Programa de Pós-Graduação em Política Social. V. 18, n. 39, julho-dezembro, 2016.

SOARES, Laura. Reforma da previdência e seguridade social: equidade de gênero e raça. Brasília: CFEMEA, 2003. 
STN. Relatórios resumidos da execução orçamentária do governo federal e outros demonstrativos, dezembro de 2008 a dezembro de 2016. Brasília: Tesouro Nacional, jan. 2017.

TEIXEIRA, Sandra Oliveira. Participação e controle democrático sobre o orçamento público federal em um contexto de crise do capital. Dissertação (Doutorado em Serviço Social) - Universidade Estadual do Rio de Janeiro, Rio de Janeiro, 2012.

THEODORO, Mário. A PEC 241 é a única saída para a crise fiscal? Boletim Legislativo, Brasília, Senado Federal, nov. 2016.

VILLELA, Luiz; LEMGRUBER, Andrea; JORRATT, Michael. Los presupuestos de gastos tributarios: conceptos y desafíos de implementación. Washington, IDB working paper series, n. 131, dez. 2009.

ZANGHELINI, Airton et al. Desoneração da folha de pagamento: oportunidade ou ameaça? Brasília: Anfip e Fundação Anfip, 2013. 